\title{
LC Compensators Based on Transmission Loss Minimization for Nonlinear Loads
}

\author{
Ahmed Faheem Zobaa, Senior Member, IEEE, and Abdel Aziz, Member, IEEE
}

\begin{abstract}
This paper presents a method employing the penalty function search algorithm to determine the $L C$ compensator value for the optimal power factor correction in nonsinusoidal systems. The objective of the proposed method is to minimize the transmission loss while the power factor and efficiency are taken as constraints and utilized in order to solve the multiobjective optimization problem by transforming it into a single objective one. Examples show that the load nonlinearity can have a significant impact on optimal compensator sizes.
\end{abstract}

Index Terms-Harmonics, power factor, reactive power optimization.

\section{INTRODUCTION}

$\mathbf{T}$ HE increasing proliferation of electronic equipment and appliances connected to the power line represents an important, growing challenge to power providers and users alike. These nonlinear loads degrade power quality because they reduce the power factor and introduce harmonic current. The power factor is of great concern to the utilities because low power factor results in harmonic currents, which propagate through the system and produce potentially dangerous harmonic voltages. Amplification of harmonic currents and voltages can have detrimental effects on other elements of the system [1]. On the other hand, if a nonlinear load generates significant harmonic currents locally, tuned filters [2], [3] may be installed to prevent the currents from being injected into the system. However, such filters are resorted only for heavily nonlinear loads because of the high cost. An important side effect of adding a filter is that it creates a sharp parallel resonance point at a frequency below the notch frequency [4]. This resonant frequency must be safely away from any significant harmonic. Filters are commonly tuned slightly lower than the harmonic to be filtered so as to provide a margin of safety in case of any change in system parameters. If they were tuned exactly to the harmonic, changes in either capacitance or inductance with temperature or failure might shift the parallel resonance into the harmonic. This might be worse than without a filter because the resonance is generally very sharp. That is why filters are added to the system starting with the lowest problem harmonic. For example, installing a seventh-harmonic filter usually requires a fifth-harmonic filter to be installed as well. The new parallel resonance with a seventh filter only would be very near the fifth, which is generally disastrous. In [5], both the equivalent

Manuscript received January 8, 2003; revised March 21, 2003. Paper no. TPWRD-00009-2003.

The authors are with the Electrical Power and Machines Department, Faculty of Engineering, Cairo University, Giza 12613, Egypt (e-mail: a.zobaa@eng.cu.edu.eg).

Digital Object Identifier 10.1109/TPWRD.2004.835426 source and load are considered to generate harmonics. The different criteria for the design of the $L C$ compensator: i) maximizing power factor, ii) minimizing transmission loss, and iii) maximizing transmission efficiency, are discussed. While discussing such criteria, the nonlinearity of the load by using direct polytope search method should be taken into account. In [6], the manufacturer's standard values for power shunt capacitors are taken into consideration. These values are considered as constraints in the sense that the solution for the capacitor should be one of the standard values. The different criteria for the design of the $L C$ compensator are discussed by using the golden section search method. Such criteria are discussed to compare the values obtained in [6] with real practical values in the market. Reference [7] formulates the problem of minimizing the transmission losses with expressions for the power factor and efficiency taken as constraints neglecting the harmonic contents of the nonlinear loads. Reference [8] shows the voltage and reactive power ratings of shunt capacitors. The inductive reactive values are almost continuous and there is little limitation on the manufacturer's values.

This paper generalizes the method used in [7], taking into account the nonlinearity of the loads, the frequency-dependent nature of the supply source, compensator values which would create resonant conditions, the effect of the transmission-line impedance on the load voltage, and the manufacturer's standard values for power shunt capacitors. The major attribute of this method is that it, unlike conventional approaches, guarantees convergence to the optimal solution. Finally, the contribution of the newly developed method is demonstrated in examples taken from previous publications.

\section{HARMONIC MODELING}

References [9]-[12] demonstrate the representation of the power system loads and extended networks. Nonlinear loads are commonly represented by ideal current source at their characteristic frequencies. Characteristic harmonic orders $K$ and the harmonic injection currents $I_{L K}$ of a line-commutated converter, operating under ideal conditions, are [9]

$$
\begin{aligned}
K & =n * p \pm 1 \\
I_{L K} & =\frac{I_{1}}{K}
\end{aligned}
$$

respectively, where $n$ is any integer number; $p$ is the pulse number of converter; and $I_{1}$ is the fundamental current.

This model is adequate where the voltage harmonic distortion $\left(\mathrm{THD}_{V}\right)$ is less than $10 \%$ [10].

The source is often represented by an impedance, found from the short-circuit test [11]. Linear loads are modeled as a resis- 
tance in parallel with an inductance, selected to account for the respective active and reactive powers at the fundamental frequency.

Finally, the linear load is represented by admittance

$$
Y_{L K}=G_{L K}-j B_{L K}
$$

or impedance

$$
Z_{L K}=R_{L K}+j X_{L K}
$$

which is a function of the order of the applied voltage harmonic frequencies. The configuration of the employed system is given in Fig. 1.

In [12], a new model for the distribution system, including nonlinear loads, is introduced. The model is based on measurements, where current and voltage measurements at two different operating conditions are used to derive an equivalent Norton model for the distribution system

$$
Z_{L K}=\frac{V_{L K}^{(1)}-V_{L K}^{(2)}}{I_{l K}^{(1)}-I_{l K}^{(2)}}
$$

To simplify the analysis, only the load model using the respective active and reactive powers at the fundamental frequency is considered while sizing compensators.

\section{DERIVATION OF THE OBJECTIVE FUNCTION}

Let

$X_{C} \quad$ capacitive reactance of the compensator;

$X_{L} \quad$ inductive reactance of the compensator;

$R \quad$ compensator resistance at the fundamental frequency;

$R_{T K}, X_{T K} \quad$ resistance and reactance of the source found from the short-circuit test at the fundamental frequency;

$R_{L K}, X_{L K} \quad$ resistance and reactance of the load selected to account for the respective active and reactive powers at the fundamental frequency.

Then

$$
\begin{aligned}
Z_{C K} & =R+j\left(K X_{L}-\frac{X_{C}}{K}\right) \\
Z_{C L K} & =\frac{\left(R_{C L K}+j X_{C L K}\right)}{\left(Z_{L K}+Z_{C K}\right)}
\end{aligned}
$$

where

where

$$
\begin{aligned}
& R_{C L K}=R R_{L K}-X_{L K}\left(K X_{L}-\frac{X_{C}}{K}\right) \\
& X_{C L K}=R X_{L K}+R_{L K}\left(K X_{L}-\frac{X_{C}}{K}\right) \\
& Z_{T L K}=\frac{\left(R_{T L K}+j X_{T L K}\right)}{\left(Z_{T K+} Z_{L K}\right)}
\end{aligned}
$$

$$
\begin{aligned}
R_{T L K} & =R_{T K} R_{L K}-X_{T K} X_{L K} \\
X_{T L K} & =R_{T K} X_{L K}+X_{L K} R_{L K} \\
Z & =Z_{T K}+Z_{C L K} .
\end{aligned}
$$

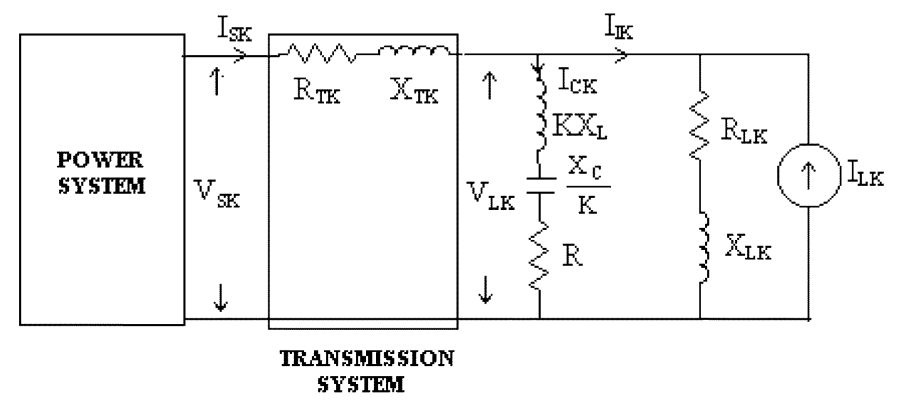

Fig. 1. Power system under study with shunt $L C$ compensator.

Following the previous definitions, the compensated line current $\left(I_{S K}\right)$ and the load voltage $\left(V_{L K}\right)$ at each harmonic order $(K)$ are given, respectively, by the following equations:

$$
\begin{aligned}
I_{S K} & =\frac{V_{S K}(A R+j B R)+I_{L K} C R}{A_{I K}+j A_{J K}} \\
V_{L K} & =\frac{V_{S K}(C R)-I_{L K}(D R * E R)}{A_{I K}+j A_{J K}}
\end{aligned}
$$

where

$$
\begin{array}{ll}
A R & R+R_{L K} ; \\
B R & \left(X_{L K}+K_{X L}-X_{C} / K\right) ; \\
C R & R_{C L K}+j X_{C L K} ; \\
D R & R+j\left(K_{X L}-X_{C} / K\right) ; \\
E R & R_{T L K}+j X_{T L K} ; \\
A_{I K} & R_{T L K}+R\left(R_{L K}+R_{T K}\right)-\left(X_{L K}+X_{T K}\right)\left(K_{X L}-\right. \\
& \left.X_{C} / K\right) ; \\
A_{J K} & X_{T L K}+R\left(R_{L K}+X_{T K}\right)+\left(R_{L K}+R_{T K}\right)\left(K_{X L}-\right. \\
& \left.X_{C} / K\right) .
\end{array}
$$

The compensated power factor at the load is given as

$$
P F=\frac{P_{L}}{V_{L} I_{S}}=\frac{\sum G_{L K} V_{L K}^{2}}{\sqrt{\sum I_{S K}^{2} \sum V_{L K}^{2}}} .
$$

The transmission loss is given as

$$
T L=\sum_{K} I_{S K}^{2} R_{T K}
$$

The transmission efficiency is given as

$$
\eta=\frac{P_{L}}{P_{S}}=\frac{\sum G_{L K} V_{L K}^{2}}{\sum I_{S K}^{2} R_{T K}+\sum G_{L K} V_{L K}^{2}} .
$$

\section{HARMONIC RESONANCE CONSTRAINT}

System resonant conditions are the most important factors affecting system harmonic levels. Parallel resonance is high impedance to the flow of harmonic current, while series resonance is low impedance to the flow of harmonic current [13]. In actual electrical systems utilizing power factor correction, both types of resonance or a combination of both may occur if the resonant point happens to be close to one of the frequencies generated by harmonic sources in the system.

For the system configuration given in Fig. 1, the driving point impedance can be determined by the following equation:

$$
Z=\frac{\left(R_{T K}+j X_{T K}\right)+\left(R_{C L K}+j X_{C L K}\right)}{\left(Z_{L K}+Z_{C K}\right)} .
$$


Setting the imaginary part of this impedance equal to zero, series resonance, results in the following quadratic equation:

$$
A_{1}\left(K X_{L}-\frac{X_{C}}{K}\right)^{2}+A_{2}\left(K X_{L}-\frac{X_{C}}{K}\right)+A_{3}=0
$$

where $A_{1}$ equals $X_{T K}+X_{L K} ; A_{2}$ is equal to $R_{L K}^{2}+X_{L K}^{2}+2 X_{L K} X_{T K} ;$ and $A_{3}$ equals $R^{2} X_{L K}+X_{T K}\left[\left(R+R_{L K}\right)^{2}+X_{T K}^{2}\right]$.Solving for finding $X_{L}$ and $X_{C}$

$$
K X_{L}-\frac{X_{C}}{K}=\frac{-A_{2} \pm \sqrt{A_{2}^{2}-4 A_{1} A_{3}}}{2 A_{1}} .
$$

Hence, using only the set values for shunt capacitors, we can obtain values for the inductive reactance since (8) will then become a one-variable equation in $X_{L}$ only.

Note that for sufficiently large load resistance and/or load reactance, (8) reduces to

$$
K X_{L}-\frac{X_{C}}{K}+X_{T K}=0
$$

which then represents only the series resonance, that represents all possible combinations of $X_{C}$ and $X_{L}$ values which result in resonance between the transmission impedance and compensated load. Under these conditions, the power factor will reach a minimum. It is evident that the number of series resonance lines will depend on the number of harmonics present in the transmission source.

\section{SKIN EFFECT CONSTRAINT}

Skin effect is an alternating current phenomenon where the current in a conductor tends to flow more densely near the outer surface of a conductor than in the center area. Skin effect will be applied in the analysis to account for the impact on the system impedance of the frequency dependence of the resistive component of the load. On utilizing voltages, such as industrial power systems, the equivalent system reactance is often dominant by the service transformer impedance [14]. For lines and cables, an estimated correction factor [15] for skin effect is applied by increasing the resistance with frequency by

or

$$
R=R *\left[1+\frac{0.646 K^{2}}{192+0.518 K^{2}}\right] \text { for lines }
$$

$$
R=R *\left[0.187+0.532 K^{1 / 2}\right] \text { for cables. }
$$

For transformers, an estimated correction factor [15] for skin effect is applied by increasing the resistance with frequency by $K^{1.15}$. The exception to this rule is with some transformers. Because of stray eddy current losses, the apparent resistance of large transformers may vary almost proportionately with the frequency [16]. Finally, in most power systems, one can generally assume that the resistance does not change significantly when studying the effects of harmonics less than the ninth [14].

\section{CAPACITOR LOADING CONSTRAINT}

One problem that is to be addressed is whether the values obtained from theoretical optimization solution can be obtained from standard manufactured values. Depending on the voltage, manufacturers have discrete capacitors available. In the presented method, manufacturers standard values for shunt capacitor are taken into consideration. The standard values are considered as constraints in the sense that the capacitor chosen should be one of these values.

\section{Proposed Solution of the Problem}

The power factor $P F$, the transmission loss $T L$, and the transmission efficiency $\eta$ can be expressed as functions of $X_{C}$ and $X_{L}$ using (4)-(6). Each value of the reactive power ratings $Q_{C i}$ of the particular voltage [8] is used to calculate the corresponding value of $X_{C i}$. This value is then substituted into the objective function to become one variable equation in $X_{L}$, which can be solved by using the penalty function method.

After formulating the objective function and the constraints, the problem addressed in this study becomes

$$
\begin{aligned}
\text { Minimize } & T L\left(X_{C i}, X_{L}\right) \\
\text { Subject to : } & 0.9 \leq P F\left(X_{C i}, X_{L}\right) \leq 1.0 \\
& 0.85 \leq \eta\left(X_{C i}, X_{L}\right) \leq 1.0 \\
& X_{C i}, X_{L} \text { is not part of the solution of (8). }
\end{aligned}
$$

Naturally, the solution will satisfy the upper limit of the power factor and efficiency constraints. Power factor in distribution systems may be allowed within certain limits according to the authority, and similarly for the efficiency so the presented method will generalize the limits of the constraints.

This problem can be rewritten in the form

$$
\begin{aligned}
\text { Minimize } & T L\left(X_{C i}, X_{L}\right) \\
\text { Subject to : } & g_{1}\left(X_{C i}, X_{L}\right)=0.9-P F\left(X_{C i}, X_{L}\right) \leq 0.0 \\
& g_{2}\left(X_{C i}, X_{L}\right)=P F\left(X_{C i}, X_{L}\right)-1.0 \leq 0.0 \\
& g_{3}\left(X_{C i}, X_{L}\right)=0.85-\eta\left(X_{C i}, X_{L}\right) \leq 0.0 \\
& g_{4}\left(X_{C i}, X_{L}\right)=\eta\left(X_{C i}, X_{L}\right)-1.0 \leq 0.0 \\
& X_{C i}, X_{L} \text { is not part of the solution of }(8) .
\end{aligned}
$$

Note that in order to have the algorithm to guarantee convergence, the objective function has to be a unimodal function [17]. Due to the resonant conditions, there might be local minimums to which the solution will converge. To avoid this problem, the precalculated compensator values for series resonance will be used to subdivide the entire search region into numerous small regions. Within these regions, the local minimums are identified and, hence, the global minimum. Note that the square of the root mean square (rms) value of the line current at a given harmonic order $\left(I_{S K}^{2}\right)$ is a unimodal (convex) function. Consequently, within these regions, the objective function $T L$ is also convex function [18]. As a result, the convergence to an optimal solution is guaranteed.

\section{SEARCH AlgORIthM}

The suggested search algorithm is discussed below. 
Step 1: Choose the first value of the standard manufactured reactive power rating of capacitors in kvar [8]

$$
Q_{C i}=\left\{Q_{C 1}, Q_{C 2} \ldots Q_{C n}\right\}
$$

where $n$ is the number of discrete values available for the particular voltage rating used and $i$ has a starting value of 1 .

Step 2: Using only the selected value of $Q_{C i}$, calculate $X_{C i}$ from the following equation:

$$
X_{C i}=\frac{V_{S I}^{2}}{Q_{C i}} .
$$

Substitute the value of $X_{C i}$ into (8) to become one variable problem in $X_{L}$, and solve it to get the precalculated inductor values for series resonance. These values are used to subdivide the entire search region into small regions. Step 3: Let penalty parameter $\mu>1$, scalar $\beta>0$, and $J=1$. Starting with $X_{L}^{(J)}$ to solve the following problem:

$$
\text { Min. } T L\left(X_{C i}, X_{L}\right)+\sum \mu_{m}\left(\max \left[0, g_{m}\left(X_{C i}, X_{L}\right)\right]\right) \text {. }
$$

For a certain value of $\mu_{m}^{(J)}$, the golden search method [1] can be applied for obtaining the optimal $X_{L}^{(J+1)}$. According to the penalty function method, the value of $\mu_{m}^{(J)}$ is updated using

$$
\mu_{m}^{(J+1)}=\beta \mu_{m}^{(J)} \text {. }
$$

Step 4: The previous step is repeated until convergence is achieved using

$$
\mu_{m}^{(J)}\left(\max \left[0, g_{m}\left(X_{C i}, X_{L}^{(J+1)}\right)\right]\right)<\epsilon .
$$

Step 5: If $i=n$ stop; otherwise, replace $i$ by $(i+1)$ and go to step 2 .

Step 6: After stopping, scan through to get the global minimum.

Reference [19] shows that the starting penalty parameter value $\mu^{(0)}=10$. Values of $\beta$ are in the range $0.1-0.5$ work well for most problems. The algorithm will stop when a feasible point will be reached or when the relative change in the objective function is small (less than $\epsilon=10^{-6}$ ).

In the optimization process, the resistance of the compensator reactor has been neglected due to its small value with respect to its fundamental reactance (less than 5\%) [20].

\section{EXAMPLES AND Simulated RESUlts}

Four cases of an industrial plant were simulated using the optimization method; the numerical data were primarily taken from an example in [13] where the inductive three-phase load is $5100 \mathrm{~kW}$ with a displacement factor $(d P F)$ of 0.7165 . The
TABLE I

SYSTEM PARAMETERS AND SOURCE HARMONICS

\begin{tabular}{c|c|c|c|c}
\hline $\begin{array}{c}\text { PARAMETERS \& } \\
\text { HARMONICS }\end{array}$ & CASE 1 & CASE 2 & CASE 3 & CASE 4 \\
\hline Short Circuit MVA & 150 & 80 & 80 & 80 \\
\hline $\mathrm{R}_{\mathrm{T} 1}(\Omega)$ & 0.01154 & 0.02163 & 0.02163 & 0.02163 \\
\hline $\mathrm{X}_{\mathrm{T} 1}(\Omega)$ & 0.1154 & 0.2163 & 0.2163 & 0.2163 \\
\hline $\mathrm{R}_{\mathrm{L} 1}(\Omega)$ & 1.742 & 1.742 & 1.742 & 1.742 \\
\hline $\mathrm{X}_{\mathrm{L} 1}(\Omega)$ & 1.696 & 1.696 & 1.696 & 1.696 \\
\hline $\mathrm{V}_{\mathrm{S} 1}(\mathrm{kV})$ & 2.4 & 2.4 & 2.4 & 2.4 \\
\hline $\mathrm{V}_{\mathrm{S} 3}\left(\% \mathrm{~V}_{\mathrm{S} 1}\right)$ & 0 & 0 & 0 & 3 \\
\hline $\mathrm{V}_{\mathrm{S} 5}\left(\% \mathrm{~V}_{\mathrm{S} 1}\right)$ & 4 & 4 & 5 & 5 \\
\hline $\mathrm{V}_{\mathrm{S} 7}\left(\% \mathrm{~V}_{\mathrm{S} 1}\right)$ & 3 & 3 & 3 & 3 \\
\hline $\mathrm{V}_{\mathrm{S} 11}\left(\% \mathrm{~V}_{\mathrm{S} 1}\right)$ & 0 & 0 & 2 & 2 \\
\hline $\mathrm{V}_{\mathrm{S} 13}\left(\% \mathrm{~V}_{\mathrm{S} 1}\right)$ & 0 & 0 & 1 & 1 \\
\hline $\mathrm{I}_{\mathrm{L} 3}(\mathrm{~A})$ & 0 & 0 & 304 & 304 \\
\hline $\mathrm{I}_{\mathrm{L} 5}(\mathrm{~A})$ & 33 & 33 & 33 & 33 \\
\hline $\mathrm{I}_{\mathrm{L} 7}(\mathrm{~A})$ & 25 & 25 & 25 & 25 \\
\hline $\mathrm{I}_{\mathrm{L} 9}(\mathrm{~A})$ & 0 & 0 & 26 & 26 \\
\hline $\mathrm{I}_{\mathrm{L} 11}(\mathrm{~A})$ & 8 & 8 & 8 & 8 \\
\hline $\mathrm{I}_{\mathrm{L} 13}(\mathrm{~A})$ & 9 & 9 & 9 & 9 \\
\hline Uncompensated PF $(\%)$ & 71.58 & 71.57 & 68.50 & 68.54 \\
\hline & & & &
\end{tabular}

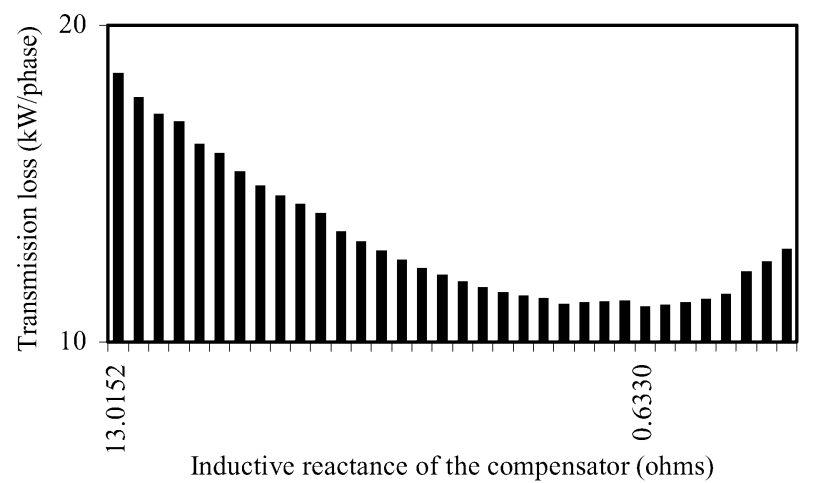

(a)

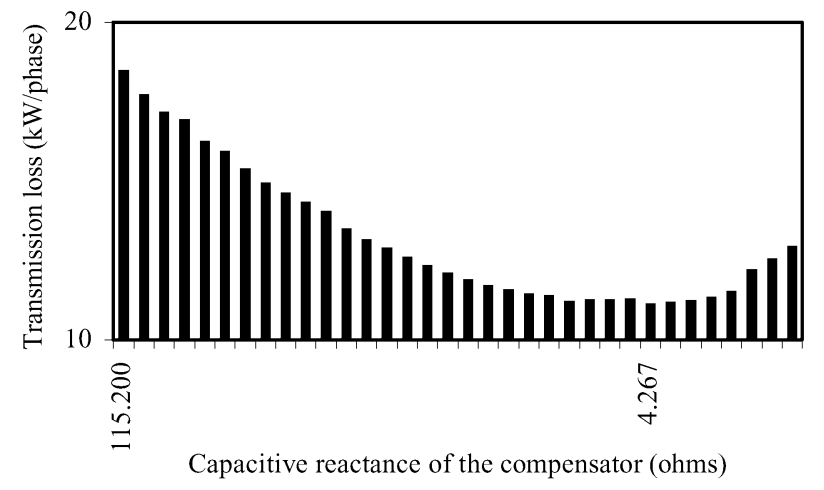

(b)

Fig. 2. Global minimum points for case 4 during the search method. (a) TL against $X_{L}$. (b) TL against $X_{C}$.

60 -cycle supply bus voltage is $4.16 \mathrm{kV}$ (line-to-line). The resistance and fundamental reactance values are given in Table I. In this study, it is assumed that the load harmonics are not sufficiently serious to suggest tuned filters, but when combined with source harmonics, the use of a pure capacitive compensator would degrade the power factor and overload equipment. Consequently, an $L C$ compensator is selected.

Fig. 2 shows the improvement in choosing the value of $X_{L}$ during the search method and how it affects the objective function. 


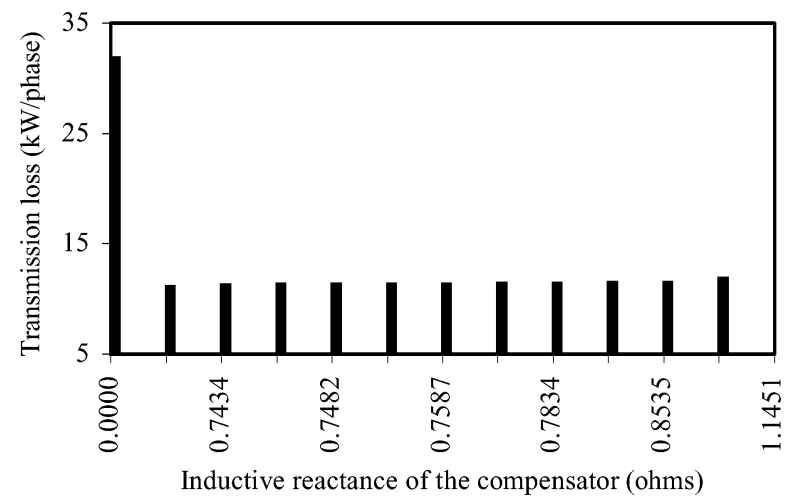

Fig. 3. Global and local minimum points for case 4 .

TABLE II

Simulated Results for the PRESENTEd OPtimization Method

\begin{tabular}{l|c|c|c|c|c|c}
\hline CASE & $\begin{array}{c}\mathrm{X}_{\mathrm{C}} \\
(\Omega)\end{array}$ & $\begin{array}{c}\mathrm{X}_{\mathrm{L}} \\
(\Omega)\end{array}$ & $\begin{array}{c}\mathrm{PF} \\
(\%)\end{array}$ & $\begin{array}{c}\mathrm{I}_{\mathrm{S}} \\
(\mathrm{A})\end{array}$ & $\begin{array}{c}\eta \\
(\%)\end{array}$ & $\begin{array}{c}\mathrm{TL} \\
(\mathrm{kW})\end{array}$ \\
\hline 1 & 4.27 & 0.827 & 99.65 & 705.85 & 99.66 & 5.75 \\
\hline 2 & 4.27 & 0.743 & 99.72 & 701.40 & 99.36 & 10.64 \\
\hline 3 & 4.61 & 0.654 & 97.60 & 711.52 & 99.34 & 10.95 \\
\hline 4 & 4.27 & 0.633 & 97.52 & 715.99 & 99.34 & 11.09 \\
\hline
\end{tabular}

TABLE III

SimUlated RESUlts FOR THE OPTIMIZATION METHOD IN [21]

\begin{tabular}{c|c|c|c|c|c}
\hline CASE & $\begin{array}{c}\mathrm{X}_{\mathrm{C}} \\
(\Omega)\end{array}$ & $\begin{array}{c}\mathrm{PF} \\
(\%)\end{array}$ & $\begin{array}{c}\mathrm{I}_{\mathrm{S}} \\
(\mathrm{A})\end{array}$ & $\begin{array}{c}\eta \\
(\%)\end{array}$ & $\begin{array}{c}\mathrm{TL} \\
(\mathrm{kW})\end{array}$ \\
\hline 1 & 7.81 & 85.24 & 807.64 & 99.54 & 7.53 \\
\hline 2 & 3.12 & 93.84 & 751.45 & 99.28 & 12.21 \\
\hline 3 & 3.02 & 91.66 & 770.77 & 99.25 & 12.85 \\
\hline 4 & 2.85 & 87.22 & 812.64 & 99.18 & 14.28 \\
\hline
\end{tabular}

Fig. 3 shows the location of the global minimum point and the local minimum points, which are located in the subdivisions where the resonant conditions exist.

Comparison of the results: Table II shows that a lower shortcircuit capacity corresponds to a higher power factor at the same conditions. This is to be expected since with higher transmission impedance, less harmonic current will flow into the compensated load, cases 1 and 2. Also, it is shown that additional harmonic contents result in lower power factor. This is caused by the increase in compensated line current due to the additional harmonics, cases 3 and 4. Comparing these results with Table II for the same system data but with the load being linear, we realized a degraded power factor, a high line current, and, hence, an increase in transmission loss and a decrease in the transmission efficiency. Table III shows the required capacitive reactance, the power factor, the supply current, the efficiency, and the transmission loss for the same system data but with the load being linear.

Finally, in the IEEE Standard 519-1992 [13], the objectives of the nonlinear load harmonic current limits are to limit the maximum individual harmonic voltage to $3 \%$ of the fundamental voltage and the total harmonic distortion of the voltage to $5 \%$.
TABLE IV

HARMONIC Distortions AND DisPLACEMENT FACTOR AFTER COMPENSATION

\begin{tabular}{c|c|c|c}
\hline CASE & $\mathrm{THD}_{\mathrm{I}}(\%)$ & $\mathrm{THD}_{\mathrm{V}}(\%)$ & $\mathrm{dPF}(\%)$ \\
\hline 1 & 7.32 & 4.22 & 99.99 \\
\hline 2 & 6.43 & 3.93 & 99.99 \\
\hline 3 & 18.28 & 5.55 & 99.34 \\
\hline 4 & 21.68 & 5.92 & 99.92 \\
\hline
\end{tabular}

Table IV shows the distortion levels and the displacement factor after compensation when taking harmonic components into account. The resultant values all come out well within standard limits except cases 3 and 4 where the load harmonics may be sufficiently serious to suggest tuned filters. It is shown that in all cases, the proposed method improves the performance of the system under study.

\section{CAPACITOR LOADING STANDARDS}

ANSI/IEEE Standard 18-1992 [8] specifies the following continuous capacitor ratings:

1) $135 \%$ of nameplate kvar;

2) $110 \%$ of rated rms voltage (including harmonics but excluding transients);

3) $180 \%$ of rated rms current (including fundamental and harmonic current);

4) $120 \%$ of peak voltage (including harmonics).

The capacitor bank data for case 1 are

bank rating: $4050 \mathrm{kvar}$;

voltage rating: $4160 \mathrm{~V}$ (L-L);

operating voltage: $4160 \mathrm{~V}$ (L-L);

supplied compensation: 4050 kvar;

fundamental current rating: $562.08 \mathrm{~A}$;

fundamental frequency: $60 \mathrm{~Hz}$;

capacitive reactance: $4.267 \Omega$;

voltage distortion: $0.71 \%$;

rms capacitor voltage: $2966.22 \mathrm{~V}$;

capacitor current distortion: $3.74 \%$;

rms capacitor current: $695.68 \mathrm{~A}$.

The fundamental current full-load current for the 4050-kvar capacitor bank without the series inductor is determined from

$$
I_{C}=\frac{4050 * 1000}{\sqrt{3} * 4160}=562.08 \mathrm{~A} .
$$

The capacitor is subjected principally to four harmonics: the fifth, the seventh, the eleventh, and the thirteenth. This results in $3.40 \%$ fifth-harmonic current, $1.51 \%$ seventh-harmonic current, $0.18 \%$ eleventh-harmonic current, and $0.32 \%$ thirteenthharmonic current (Table V).

Table V summarizes capacitor evaluation for case 1 that is designed to help evaluate the various capacitor duties against the standards.

Finally, Table VI shows that the resultant values all come out well below standard limits.

\section{CONCLUSION}

A mathematical model is developed and a solution method is presented for an optimal power factor correction of distribution circuits having nonlinear loads. The main contribution of this 
TABLE V

CAPacitor CAPabilities for CASE 1 When Supplied by NONSINUSOIDAL VOLTAGES

\begin{tabular}{c|c|c|c|c|c}
\hline $\begin{array}{c}\text { Harmonic } \\
\text { No. }\end{array}$ & $\begin{array}{c}\text { Frequency } \\
(\mathrm{Hz})\end{array}$ & $\begin{array}{c}\text { Voltage } \\
(\%)\end{array}$ & $\begin{array}{c}\text { Voltage } \\
(\mathrm{V})\end{array}$ & $\begin{array}{c}\text { Current } \\
(\%)\end{array}$ & $\begin{array}{c}\text { Current } \\
(\mathrm{A})\end{array}$ \\
\hline 1 & 60 & 100.00 & 2966.1 & 100 & 695.2 \\
\hline 2 & 120 & 0.00 & 0.00 & 0.00 & 0.00 \\
\hline 3 & 180 & 0.00 & 0.00 & 0.00 & 0.00 \\
\hline 4 & 240 & 0.00 & 0.00 & 0.00 & 0.00 \\
\hline 5 & 300 & 0.68 & 26.20 & 3.40 & 23.70 \\
\hline 6 & 360 & 0.00 & 0.00 & 0.00 & 0.00 \\
\hline 7 & 420 & 0.22 & 6.70 & 1.51 & 10.50 \\
\hline 8 & 480 & 0.00 & 0.00 & 0.00 & 0.00 \\
\hline 9 & 540 & 0.00 & 0.00 & 0.00 & 0.00 \\
\hline 10 & 600 & 0.00 & 0.00 & 0.00 & 0.00 \\
\hline 11 & 660 & 0.02 & 1.60 & 0.18 & 1.20 \\
\hline 12 & 720 & 0.00 & 0.00 & 0.00 & 0.00 \\
\hline 13 & 780 & 0.02 & 0.40 & 0.32 & 2.20 \\
\hline
\end{tabular}

TABLE VI

CAPACITOR BANK LIMITS FOR CASE 1

\begin{tabular}{c|c|c|c}
\hline Item & Calculated (\%) & Limit (\%) & Exceeds limit \\
\hline Peak voltage & 100.94 & 120.00 & No \\
\hline rms voltage & 100.00 & 110.00 & No \\
\hline rms current & 100.07 & 180.00 & No \\
\hline kvar & 100.07 & 135.00 & No \\
\hline
\end{tabular}

work is the introduction of nonlinear loads on the problem, and also the proposed solution method.

For nonlinear loads, it is suggested to use $L C$ compensators. Such compensators have dual purposes. The first is that they act as compensators to improve the power factor of the nonlinear loads. Second, they act as filters of the harmonic load currents; thus preventing the proliferation of the network with these currents. It is shown that the $L C$ compensator sizes can be quite different when nonlinear loads are present in a system when compared to those found by neglecting harmonic components.

Four cases are tested, and the general performance of the proposed method is satisfactory, providing transmission losses reduction, improvement of distortion levels, and power factor correction, compared with other published results.

\section{REFERENCES}

[1] R. F. Chu and R. H. Avendano, "A direct method for identifying the optimal power factor correction in nonsinusoidal systems," IEEE Trans. Power App. Syst., vol. PAS-104, pp. 959-964, Apr. 1985.

[2] D. Zaninelli, "Nonlinear passive filters in power systems," in Proc. IEEE Power Eng. Soc. Summer Meeting, vol. 2, 2000, pp. 773-777.

[3] W. Jewell, "Filtering dispersed harmonic sources on distribution," IEEE Trans. Power Delivery, vol. 15, pp. 1045-1051, July 2000.

[4] R. C. Dugan, M. F. McGranaghan, and H. W. Beaty, Electrical Power Systems Quality. New York: McGraw-Hill, 1996.

[5] M. M. Abdel-Aziz, E. E. A. El-Zahab, A. M. Ibrahim, and A. F. Zobaa, "Comparing capacitive and $L C$ compensators for power factor correction," in Proc. 10th Int. Conf. Harmonics and Quality of Power, Rio de Janeiro, Brazil, Oct. 6-9, 2002.

[6] - "Practical considerations on power factor correction for nonlinear loads," in Proc. 10th Int. Conf. Harmonics and Quality of Power, Rio de Janeiro, Brazil, Oct. 6-9, 2002.

[7] — "On the economic selection of capacitive compensator sizes in nonsinusoidal conditions," IEEE Power Eng. Rev., vol. 22, no. 10, pp. 47-48, Oct. 2002

[8] IEEE Standards for Shunt Power Capacitors, IEEE Std. 18-1992, 1992.
[9] R. E. Owen, M. F. McGranaghan, and J. R. Vivirito, "Distribution system harmonics: Control of large power converters," IEEE Trans. Power App. Syst., vol. PAS-101, pp. 644-652, Mar. 1982.

[10] M. F. McGranaghan, R. C. Dugan, J. A. King, and W. T. Jewell, "Distribution feeder harmonic study methodology," IEEE Trans. Power App. Syst., vol. PAS-103, pp. 3663-3671, Dec. 1984.

[11] R. P. Stratford, "Harmonic pollution on power system-A change in philosophy," IEEE Trans. Ind. Applicat., vol. 16, pp. 617-623, Sept./Oct. 1980.

[12] S. Abdelkader, M. H. Abdel-Rahman, and M. G. Osman, "A Norton equivalent model for nonlinear loads," in Proc. Large Eng. Syst. Conf. Power Engineering, Halifax, NS, Canada, 2001, pp. 63-67.

[13] IEEE Recommended Practices and Requirements for Harmonic Control in Electrical Power Systems, IEEE Std. 519-1992, 1992.

[14] R. C. Dugan, M. F. McGranaghan, and H. W. Beaty, Electrical Power Systems Quality. New York: McGraw-Hill, 1996.

[15] P. F. Ribeiro, "Tutorial on harmonics modeling and simulation," in Proc IEEE Power Eng. Soc. Winter Meeting, Tampa, FL, Feb. 4, 1998

[16] D. E. Rice, "Adjustable speed drive and power rectifier harmonics: Their effect on power system components," in Proc. IEEE Ind. Applicat. Soc. Annu. Petroleum Chemical Industry Conf., 1984, Paper PCIC-84-52.

[17] D. A. Pierre, Optimization Theory With Applications. New York: Wiley, 1969.

[18] G. H. Hadley, Nonlinear Proframing and Dynamic Programming. Reading, MA: Addison-Wesley, 1964.

[19] M. Ben-Daya and K. S. Al-Sultan, "A new penalty function algorithm for convex quadratic programming," Eur. J. Oper. Res., vol. 101, pp. 155-163, 1997.

[20] G. G. Richards, O. T. Tan, P. Klinkhachorn, and N. I. Santoso, "Costconstrained power factor optimization with source harmonics using $L C$ compensators," IEEE Trans. Ind. Electron., vol. IE-34, pp. 266-270, May 1987.

[21] I. M. El-Amin, S. O. Duffuaa, and A. U. Bawah, "Optimal shunt compensators at nonsinusoidal bus bars," IEEE Trans. Power Syst., vol. 10, pp. 716-723, May 1995

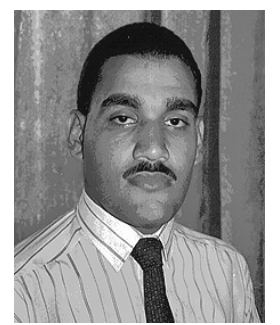

Ahmed Faheem Zobaa (M'01-SM'04) received the B.Sc. (Hons.), M.Sc., and Ph.D. degrees in electrical power and machines from Cairo University, Giza, Egypt, in 1992, 1997, and 2002, respectively.

Currently, he is an Assistant Professor in the Department of Electrical Power and Machines with the Faculty of Engineering, Cairo University. He was an Instructor in the Department of Electrical Power and Machines with the Faculty of Engineering at Cairo University from 1992 to 1997, and Teaching Assistant from 1997 to 2002 . He regularly reviews papers for eight IEEE Transactions especially all IEEE/Power Engineering Society transactions and seven journals in his areas of interest. He is author or co-author of many referred journal and conference papers. His areas of research include harmonics, compensation of reactive power, power quality, photovoltaics, wind energy, education, and distance learning. He is an Editor of IEEE Power Engineering Society Letters and an Associate Editor for the IEEE TRANSACTIONS ON INDUSTRIAL ELECTRONICS, International Journal of Power and Energy Systems, and International Journal on Modelling and Simulation.

Dr. Zobaa is a member of the IEEE Power Engineering/Industry Applications/Industrial Electronics/Power Electronics Societies, and the Internationa Solar Energy Society. He is an Editorial Board member for Electric Power Components \& Systems Journal and International Journal of Computational Intelligence.

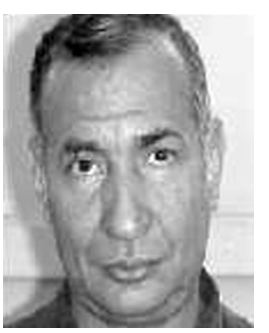

Mohamed Mamdouh Abdel Aziz (M'80) received the B.Sc. (Hons.), M.Sc., and Ph.D. degrees in electrical power and machines, Cairo University, Giza, Egypt, in 1970, 1972, and 1975, respectively.

Currently, he is a Professor in the Department of Electrical Power and Machines at Cairo University. He was an Instructor in the Department of Electrical Power and Machines, Cairo University, from 1970 to 1972. He was also a Teaching Assistant in the Department of Electrical Power and Machines at Cairo University from 1972 to 1975 . On the technical side, he is the author or coauthor of many referred journal and conference papers. His areas of research include cables, contact resistance, harmonics, power quality, photovoltaic systems, and wind energy systems. 